\title{
LABORATORY MODEL TEST OF TRANSIENT RIP CURRENTS DUE TO PSEUDO HONEYCOMB PATTERN WAVES
}

\author{
Junwoo Choi, Korea Institute of Civil Engineering \& Building Technology, jwchoi@kict.re.kr \\ Min Roh, Korea Institute of Civil Engineering \& Building Technology, rohmin@kict.re.kr \\ Hyung-sik Hwang, Korea Institute of Civil Engineering \& Building Technology, hwanghyungsik@kict.re.kr
}

\section{INTRODUCTION}

The Haeundae coast of South Korea is famous for its beautiful beach, but the rip current, from which the beachguards rescue more than 100 people every summer at the beach, is now a notorious phenomenon. The large-scale Haeundae rip current is known to be a transient rip current caused by multi-directional wave trains rather than the topography-induced rip current, for example, due to a gap of sandbar. In other words, the rip current seems develop along the cross-shore nodal line area in the honeycomb wave-crest pattern (Dalrymple et al., 2011) which are generated in a shallow water when two wave trains propagate with slightly different wave directions (i.e., interference pattern). The wave pattern is formed by the refraction of incident swells over submerged shoals and ridges of the Haeundae coast. The Haeundae rip current is an example explained by the vortex generation due to the ends of wave crests in Peregrine(1998), which is known of the basic generation mechanism of rip currents(Johnson and Pattiaratchi, 2006; Clark et al., 2012; Feddersen, 2014).

To understand the generation mechanism and verify the numerical model results of the Haeundae rip current, the laboratory experiment was planned. This study showed the preliminary laboratory observations which include the pseudo honeycomb pattern of incident waves and its resultant rip current.

\section{METHOD}

The laboratory experiment was conducted in the wave basin in $40 \mathrm{~m}(\mathrm{~L}) \times 30 \mathrm{~m}(\mathrm{~W}) \times 1.2 \mathrm{~m}(\mathrm{H})$ with the transversely constant bathymetry which has the equilibrium beach slope according to an empirical function(Dean, 1991). The generation of two wave trains with slightly different direction in the laboratory basin has a limitation because of lateral wall boundary reflections. To produce a pseudo node area of the honeycomb wave-crest pattern or the successive ends of the wave crests, two groups of wave-maker piston panels were operated with out-ofphase in the transverse direction. In order to observe the rip current developing along the pseudo node area, approximately two thousands particles (i.e., holed plastic balls) were released at the shoreline after wave generation and the video cameras, installed on the ceiling of the laboratory ( $8 \mathrm{~m}$ high from the basin bottom), were utilized to record the motion of the particles. In addition, the wave height distribution was observed around the rip current developing through the successive ends of wave-crests (i.e., the node of the honeycomb wave-crest patterns).

\section{RESULT}

The snapshot images of the video camera on the laboratory ceiling shown in Figure 1 presented the evolution of the transient rip current caused by the vortex generation mechanism and the gradient of the wave-induced momentum flux. The wave height distribution and water surface variation were observed around the pseudo nodal line area.
As a result, it was confirmed that the nodal line area of the honeycomb wave pattern has remained low wave heights, and the transient rip current developed along the area. From the present preliminary experiment, it is inferred that the transient rip current can be observed in the laboratory by using the method of generating the pseudo node area of honeycomb wave-crest pattern (i.e., the pattern of successive ends of wave-crest lines). (a)

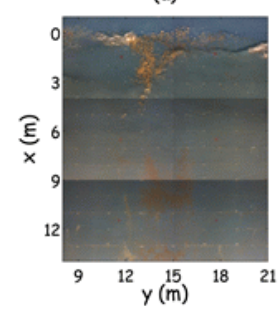

(b)

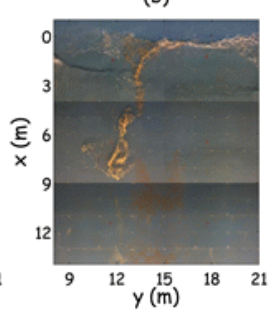

(c)

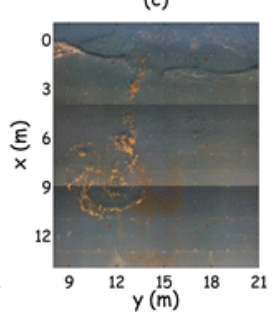

Figure 1 - Snapshot of the experiment case $5(\mathrm{H}=10 \mathrm{~cm}$,

$\mathrm{T}=2.4 \mathrm{~s}$ ) presenting the gap of wave crests and particles moving toward the offshore due to rip current at (a) $t=90 \mathrm{~s}(\mathrm{~b})$

$$
\mathrm{t}=110 \mathrm{~s} \text { (c) } \mathrm{t}=130 \mathrm{~s} \text {. }
$$

\section{DISCUSSION}

In the future study, the characteristics of transient rip current should be observed by using various measurements. For this, the video camera images could be analyzed by using Large Scale Particle Image Velocimeter (LSPIV).

\section{ACKNOWLEDGEMENT}

This study was performed by a project of "Investigation of large swell waves and rip currents and development of the disaster response system (No. 20140057)", sponsored by the Ministry of Oceans and Fisheries.

\section{REFERENCES}

Clark, D.B., Elgar, S., and Raubenheimer, B. (2012):

Vorticity generation by short-crested wave breaking, Geophysical Research Letters, vol. 39, L24604.

Dalrymple, R.A., MacMahan, J.H., Reniers, A.J.H.M., and Nelko, V. (2011): Rip currents, Annu. Rev. Fluid Mech., vol. 43, pp. 551-581.

Dean, R. G. (1991) Equilibrium beach profiles: Principle and applications, Journal of Coastal Research, 7(1), 53-84.

Johnson, D. and Pattiaratchi, C. (2006): Boussinesq modelling of transient rip currents, Coastal Engineering, ELSEVIER, vol. 53, pp. 419-439.

Peregrine, D. H. 1998 Surf zone currents. Theoret. Comput. Fluid Dyn. 10, 295-309. 